\title{
Perbandingan Pendirian Dan Sistem Hukum Perusahaan Antar Negara Indonesia Dan Kamboja
}

\author{
Mahardyan Trymario Saputro \\ Fakultas Hukum, Universitas Indonesia \\ Jl. Salemba Raya No.4, RW.5, Kenari, Kec. Senen, Kota Jakarta Pusat, Daerah Khusus Ibukota Jakarta \\ 10430 \\ Email: mahardyan.trymario@gmail.com
}

\begin{abstract}
With the existence of a company as a business entity in the business world between Indonesia and Cambodia, it makes the arrangement of company establishment an initial concern. In Indonesia, a Company is a legal entity that is a capital partnership, established based on an agreement, carrying out business activities with capital, established based on an agreement, conducting business activities with an authorized capital wholly divided into shares and complying with the requirements stipulated in this Law and its implementing regulations. A Cambodia limited liability company (LLC) is managed by officers and directors and is funded by capital provided by the shareholders. It can be as small as a single business person or as large as a business with many shareholders. Companies provide a framework for businesses to own property, sign contracts, and engage in legal action without putting the assets of their shareholders at risk.
\end{abstract}

Keywords: Comparative Law, Corporate Law, Company Establishment, Indonesian Company Law, Cambodia Company Law

Abstrak. Dengan adanya perusahaan sebagai suatu badan usaha dalam dunia bisnis antara Negara Indonesia maupun Kamboja, menjadikan pengaturan tentang pendirian perusahaan menjadi perhatian awal. Di Indonesia Perseroan adalah badan hukum yang merupakan persekutuan modal, didirikan berdasarkan perjanjian, melakukan kegiatan usaha dengan modal, didirikan berdasarkan perjanjian, melakukan kegiatan usaha dengan modal dasar yang seluruhnya terbagi dalam saham dan memnuhi persyaratan yang ditetapkan dalam Undang-Undang ini serta peraturan pelaksanaanya. Perusahaan perseroan terbatas (LLC) kamboja dikelola oleh pejabat dan direktur dan didanai oleh modal yang disediakan oleh pemegang saham. Itu bisa sekecil satu orang bisnis atau sebesar bisnis dengan banyak pemegang saham. Perusahaan menyediakan kerangka kerja bagi bisnis untuk memiliki properti, menandatangani kontrak, dan terlibat dalam tindakan hukum tanpa menempatkan aset para pemegang sahamnya di risiko.

Kata Kunci: Perbandingan Hukum, Hukum Perusahaan, Pendirian Perusahaan, Hukum Perusahaan Indonesia, Hukum Perusahaan Kamboja

\section{PENDAHULUAN.}

Kamboja dan Indonesia merupakan negara bagian ASEAN dengan bentuk negara yang berbeda. Pertumbuhan ekonomi Indonesia dan Kamboja meningkat dengan indeks angkanya masing-masing. Dengan beracuan pada data World Bank, 2018 GDP (Gross Domestic Product) yakni meningkat sebesar 39\%, lebih rendah dibandingkan pertumbuhan GDP Kamboja yaitu diangka 70\%. Dalam indeks Kapitalisasi Pasar atau harga keseluruhan dari sebuah saham perusahaan di Indonesia lebih tinggi yaitu diangka 464.65 trilliun USD dibandingkan Kamboja diangka 30.0 trilliun USD. Indonesia juga unggul dalam indeks angka terhadap perlindungan investor minoritas sebesar 63.3 sedangkan nilai kamboja berada di angka 50 .

Dengan adanya perusahaan sebagai suatu badan usaha dalam dunia bisnis antara Negara Indonesia maupun Kamboja, menjadikan pengaturan tentang pendirian 
perusahaan menjadi perhatian penting. Model usaha yang dilakukan oleh para pelaku bisnis, baik itu pedagang, industrialis, investor, kontraktor, distributor, banker, perusahaan asuransi, pialang, agen dan lain sebagainya tidak lagi dipisahkan dari kehadiran perusahaan. Berbisnis dengan mempergunakan perusahaan, baik dalam skala kecil, menengah maupun berskala besar merupakan model yang paling banyak dan paling lazim dilakukan. Dalam sistem hukum di Indonesia, regulasi tentang perusahaan awalnya diatur dalam kitab Undang-Undang Hukum Dagang, yang kemudian diganti dengan UU No. 1 Tahun 1995 tentang Perseroan Terbatas. Karena sudah dirasakan tidak sesuai lagi dengan perkembangan hukum dan kebutuhan masyarakat, Undang-Undang No. 1 Tahun 1995 ini dicabut dan diganti dengan UU No. 40 Tahun 2007 tentang Perseroan Terbatas (Lembaran Negara Tahun 2007 No. 106, tanggal 16 Agustus 2007).

Sistem hukum di Indonesia merupakan negara dengan sistem hukum civil law. Civil Law merupakan sistem hukum yang berkembang di negara-negara Eropa daratan, dengan karakteristik; Pertama, adanya kodifikasi, alasan mengapa sistem civil law menganut paham kodifikasi antara lain karena demi kepentingan politik Imperium Romawi, disamping kepentingan lainnya diluar itu. Kodifikasi diperlukan untuk menciptakan keseragaman huum dan di tengah-tengah keberagaman hukum. Agar kebiasaankebiasaan yang telah ditetapkan sebagai peraturan raja supaya ditetapkan menajdi hukum yang berlaku secara umum, perlu dipikirkan kesatuan hukum yang berkepastian. Pemkiran itu, solusinya adalah diperlukanya suatu kodifikasi hukum. Kedua, Hakim tidak terikat pada Presiden. Menurut pendapat Paul Scholten yang mengatakan bahwa maksud pegorganisaian organ-organ negara Belanda tentang adanya pemisahan antar kekuasaan membuat undang-undang, kekuasaan peradilan dan sistem kasasi sert kekuasaan eksekutif, dan tidak dimungkinkannya kekuasaan yang satu mencampuri urusan kekuasaan lainnya, dengan cara tersebut maka terbentukla yurisprudensi. Ketiga, Peradilan menganut sistem Inkuisitorial. Kamboja adalah negara monarki konstitusional dengan menganut sistem hukum civil law.

Sistem Hukum Kamboja sebagian besar didasarkan pada sistem sipil dan peraturan perundang-undangan Prancis. Sistem Hukum Kamboja adalah statutory law system, yang berarti hampir secara kesulurahan hukum berbentuk tertulis. Statutory law system adalah hukum tertulis yang disahkan oleh badan legilatif. Ini bertentangan dengan hukum lisan atau adat; atau undang-undang pengaturan yang diundangkan oleh eksekutif atau hukum peradilan. Sumber Hukum Kamboja diklasifikasikan atas primary sources dan secondary sources. Primary sources adalah hukum formal atas otoritas negara. Secodary sources adalah kebiasaan, tradisim doktrin dan putusan hakim di kamboja. Pada tahun 2019, kamboja sedang mengalami perkembangan pesat di bidang ekonomi dan sosial. Pertumbuhan ekonomi kamboja meningkat pada angak 7\%. Jumlah turis Indonesia yang berkunjung ke Kamboja mencapai 55.753 orang atau meningkat $11.8 \%$.

\section{METODE PENELITIAN}

Berdasarkan permasalahan dan tujuannya, maka penelitian ini termasuk jenis penelitian yuridis empiris. Penelitian ini dilakukan dengan mengkaji dan melakukan perbandingan peraturan mengenai hukum perusahaan antara Negara Indonesia dan Kamboja.

Pendekatan penelitian yang digunakan dalam penelitian ini adalah pendekatan yuridis normatif. Pendekatan yuridis normatif adalah pendekatan yang dilakukan berdasarkan bahan hukum utama dengan cara menelaah teori-teori, konsep-konsep, asasasas hukum serta peraturan perundangundangan yang berhubungan dengan penelitian ini. Pendekatan ini dikenal pula dengan pendekatan kepustakaan, yakni dengan mempelajari buku-buku dan dokumen lain yang berhubungan dengan penelitian ini.

Jenis data dari penelitian ini terbagi atas dua yaitu data primer dan sekunder. Data primer dalam penelitian ini diperoleh melalui studi kepustakaan yang berkaitan dengan 
hukum perusahaan yang berlaku di Indonesia dan Kamboja. Data primer dalam penelitian ini merupakan peraturan perundang-undangan terkait yaitu Undang-Undang No. 40 Tahun 2007 Tentang Perseroan Terbatas, Law on Commercial Enterprises Cambodia 2005, Handbook Commercial Registration Minister of Commerce Cambodia 2007. Sedangkan data sekunder diperoleh dari luar objek tetapi masih berhubungan dengan tema penelitian ini. Data sekunder ini juga peneliti dapat melalui media online seperti internet yang sumber informasinya disediakan berbagai macam lembaga yang terkait serta dari studi kepustakaan antara lain buku kepustakaan,laporan penelitian hukum yaitu karya tulis/ilmiah yang berkaitan dengan permasalahan yang dibahas, makalah, surat kabar, serta sarana lain yang menyediakan layanan informasi yang berkaitan dengan pembahasan permasalahan dalam penelitian ini dan literatur yang berhubungan dengan topik penelitian penulis.

\section{Perbandingan Pengaturan Perusahaan} Indonesia dan Kamboja.

Menurut pandangan Molengraaf, perusahaan adalah keseluruhan perbuatan yang dilakukan secara terus menerus bertindak ke luar untuk memperoleh penghasilan dengan memperniagakan atau menyerahkan barangbarang atau mengadakan perjanjianperjanjian perniagaan.

Berdasarkan Hukum Indonesia, kata "Perseroan" berasal dari beberapa UndangUndang yang berlaku, salah satunya berdasarkan Pasal 1 ayat 1 Undang Nomo 40 Tahun 2007 Tentang Perseroan Terbatas:

Perseroan terbatas, yang selanjutnya disebut Perseroan, adalah badan hukum yang merupakan persekutuan modal, didirikan berdasarkan perjanjian, melakukan kegiatan usaha dengan modal, didirikan berdasarkan perjanjian, melakukan kegiatan usaha dengan modal dasar yang seluruhnya terbagi dalam saham dan memnuhi persyaratan yang ditetapkan dalam Undang-Undang ini serta peraturan pelaksanaanya.
Sedangkan berdasarkan UndangUndang Nomor 19 tahun 2003 Tentang Badan Usaha Milik Negara, Pasal 1 angka 2 bahwa Perusahaan Perseroan adalah:

Perusahaan Perseroan, yang selanjutnya disebut Persero, adalah BUMN yang berbentuk perseroan terbatas yang modalnya terbagi dalam saham yang seluruhnya atau paling sedikit $51 \%$ (lima puluh satu persen) sahamnya dimiliki oleh Negara Republik Indonesia yang tujuan utamanya mengejar keuntungan.

Sistem Hukum Indonesia membedakan Perusahaan Perseroan dengan badan hukum lainnya, penjelasan lebih lanjut mengenai perseroan merujuk pada:

1. Pasal 36 Kitab Undang-Undang Hukum Dagang :

1) Perseroan terbatas tak mempunyai sesuatu firma, dam tak memakai nama salah seorang atau lebih dari para perseroannya namun diambinyalah nama perseroan tersbut dari tujuan perusahannya semata-mata.

2) Sebelum suatu perseroan terbatas bias berdiri dengan sah, maka akta pendiriannya atau naskah dari akta tersebut harus disampaikan terlesbih dahulu kepada Menteri Kehakiman, untuk mendapt pengesahannya.

3) Untuk tiap-tiap perubahan dalam syarat-syarat pendiriannya, dan dalam hal perpanjangan waktu, harus diroleh pengesahan yang sama.

2. Pasal 38 Kitab Undang- Undang hukum Dagang :

1) Akta perseroan tersebut harus dibuat dalam bentuk otentik, atas, ancaman kebatalannya.

2) Para persero diwajibkan mendaftarkan akta itu seluruh nya beserta pengesahan yang diperolehnya dalam register umum yang disediakan untuk itu di kepantireaan Pengadilan Negeri yang mana dalam daerah hukumnya perseroanitu mempunyai tempat kedudukannya, sedangkan mereka di wajibkan pula mengumumkannys dalam Berita Negara. 
3) Segala sesuatu yang tersebut di atas berlaku juga terhadap segala perubahan dalam syarat-syarat pendiriannya, atau dalam hal waktu perseroan diperpanjangnya.

4) Ketentuan pasal 25 berlaku juga, dalam hal ini.

3. Bentuk-bentuk Perseroan

1) Pasal 7 ayat (1) bahwa " Perseroan Terbatas, yang selanjutnya disebut perseroan, adalah badan hukum yang merupakan persekutuan modal, didirikan berdasarkan perjanjian, melakukan kegiatan usaha dengan modal dasar yang seluruhnya terbagi dalam saham dan memenuhi persyaratan yang ditetapkan dalam undang-undang ini serta peraturan pelaksanaannya."

2) Pasal 7 ayat (7) bahwa "Perseroan Terbuka adalah Perseroan Publik atau Perseroan yang melakukan penawaran umum saham, sesuai dengan ketentuan peraturan perundang-undangan di bidang pasar modal."

3) Pasal 7 ayat (8) bahwa "Perseroan Publik adalah Perseroan yang memenuhi kriteria jumlah pemegang saham dan modal disetor sesuai dengan ketentuan peraturan perundangundangan di bidang pasar modal."

4. Syarat Pendirian Perseroan diatur dalam Undang-Undang Nomor 40 Tahun 2007, yaitu:

1) Pasal 7 ayat (1) "Perseroan didirikan oleh 2 (dua) orang atau lebih dengan akta notaris yang dibuat dalam bahasa Indonesia."

2) Pasal 7 ayat (2) "Setiap pendiri Perseroan wajib mengambil bagian saham pada saat Perseroan didirikan."

5. Modal dasar suatu Perseroan diatur dalam pasal 32 ayat (1), Pasal 33 ayat (1) dan Pasal 34 ayat (1) yaitu:

1) Pasal 32 ayat (1) "Modal dasar Perseroan paling sedikit Rp 50.000.000,00 (lima puluh juta rupiah)"

2) Pasal 33 ayat (1) “Paling sedikit $25 \%$ (dua puluh lima persen) dan modal dasar sebagaimana dimaksud dalam Pasal 32 harus ditempatkan dan disetor penuh."

3) Pasal 34 ayat (1) " penyetoran atas modal saham dapat dilakukan dalam bentuk uang dan/atau dalam bentuk lainnya."

6. Sistem pertanggungjawaban dalam perseroan diatur dalam pasal 97 ayat (1), ayat (3, dan ayat (5) yaitu:

1) Pasal 97 ayat (1) "Direksi bertanggung jawab atas pengurusan Perseroan sebagaimana dimaksud dalam Pasal 92 ayat (1)."

2) Pasal 97 ayat (3) "Setiap orang anggota Direksi bertanggung jawab penuh secara pribadi atas kerugian Perseroan apabila yang bersangkutan bersalah atau lalai menjalankan tugasnya sesuai dengan ketentuan sebagaimana dimaksud pada ayat (2)

3) Pasal 97 ayat (5) "Anggota Direksi tidak dapat dipertanggungjawabkan atas kerugian sebagaimana dimaksud pada ayat (3) apabila dapat membuktikan:

a. Kerugian tersebut bukan karena kesalahan atau kelalainnay;

b. Telah melakukan pengurusan dengan itikad baik dan kehatihatian untuk kepentingan dan sesuai dengan maksud dan tujuan Perseroan;

c. Tidak mempunyai benturan kepentingan baik langsung maupun tidak langsung atas tindakan pengurusan yang mengakibatkan kerugian; dan

d. Telah mengambil tindakan untuk mencegah timbul atau berlanjutnya kerugian tersebut.

Kemudian jenis-jenis urusan perusahaan dibagi menjadi beberapa hal yaitu:

1. Bukan benda yang dalam hal ini dapat berupa karyawan, pelanggan, relasi, perusahaan itu sendiri apabila perusahaan tersebut berbentuk badan hukum dan lainlain.

2. Benda bergerak 
a. Benda bergerak berwujud, misalnya, meja, kursi, computer, sepeda motor, mobil, truk, barang dagangan, dan lainlain.

b. Benda bergerak tidak berwujud, misalnya saham, obligasi, cek, wesel, bilyet giro, piutang, merek dagang, paten, nama perusahaan, dan lain-lain.

3. Benda tetap

a. Benda tetap berwujud, misalnya tanah, bangunan, kapal terdaftar, pesawat terdaftar, dan lain-lain.

b. Benda tetap tidak berwujud, misalnya hak tanggungan, hipotik, dan lain-lain.

Menurut ketentuan UUPT 2007 dalam Pasal 2 disebutkan bahwa Perseroan harus mempunyai maksud dan tujuan serta kegiatan usaha yang tidak bersebrangan dengan ketentuan peraturan perundang-undangan, ketertiban umum, dan/atau kesusilaan. Perusahaan mempunyai kegiatan usaha, sehingga perseroan mempunyai maksud dan tujuan serta kegiatan usaha yang tidak bertentangan dengan ketentuan peraturan perundang-undangan, ketertiban umum, dan/atau kesusilaan.

Dalam Pasal 1 ayat (1) Undang-undang Nomor 40 Tahun 2007 tentang Perseroan Terbatas tersebut secara tegas disebutkan bahwa perseroan adalah "badan hukum". Namun di sini perlu diperhatikan bahwa suatu perseroan, baru dapat disebut atau diakui sebagai badan hukum apabila telah memenuhi persyaratan yang ditentukan atau sesuai dengan ketentuan undang-undang.

Dalam Undang-undang Nomor 40 Tahun 2007 tentang Perseroan Terbatas Pasal 1 ayat (1) yang menegaskan bahwa perseroan terbatas adalah badan hukum perseroan dibentuk berdasarkan "perjanjian" yang artinya sekurang-kurangnya didirikan oleh dua orang/pihak dengan menganut asas perjanjian, bukan asas institusi berlaku selama ini. Sebagai akibat dibentuknya Perseroan Terbatas maka:

a. Terciptanya badan hukum (legal person/legal entity atau rechts persoon/a person in law); b. Perseroan Terbatas mempunyai rangkaian yang kekal, keberadaannya berlangsung sampai dibubarkan secara hukum ;

c. Hukum memperlakukan pemilik dan pengurus terpisah dari Perseroan Terbatas (separate legal personality - as a separate person)

d. Perseroan Terbatas sebagai manusia buatan/artificial person adalah kebalikan dari manusia atau orang (natural person).

Perjanjian yang dimaksud sebelumnya adalah suatu keadaan dimana orang yang bersedia mengikatkan kepada orang lainnya atau antara 2 (dua) orang itu saling bersepakat untuk mencapai hal terterntu. Ketentuan Pasal 1320 Kitab Undang-undang Hukum Perdata yang menyebutkan adanya persetujuan kehendak antara para pihak yang membuat suatu perjanjian (konsensus).

Setelah PT yang diakui sebagai badan hukum, akan mengakibatkan beberapa hal yang diantaranya adalah :

a. PT dapat memiliki harta kekayaan (property) atas namanya;

b. Pemilik tidak berkepentingan dalam kekayaan PT (have no interest);

c. Pemilik Pemilik tidak bertanggung jawab atas utang-utang PT;

d. Pemilik tidak bisa digugat langsung oleh kreditor, dalam hal tanggung jawab yang ditimbulkan oleh perseroan.

Badan hukum selain manusia perseorangan dianggap dapat bertindak dalam hukum mempunyai hak, kewajiban dan hubungan hukum terhadap orang atau badan yang lainnya. Badan hukum adalah suatu badan yang keberadaannya terjadi karena hukum atau undang-undang.

Status badan hukum harus memenuhi persyaratan setelah akta pendirian mendapat pengesahan Menteri terkait, perseroan memperoleh status badan hukum pada tanggal diterbitkannya keputusan menteri mengenai pengesahan badan hukum Perseroan sesuai dengan Pasal 7 ayat 4 UUPT 2007. Hak dan kewajiban badan hukum terpisah dari hak dan kewajiban anggotanya. Badan hukum (rechtpersoon) adalah badan yang dapat 
mempunyai harta, hak serta kewajiban seperti orang pribadi.

Badan hukum, yaitu kumpulan dari orang-orang bersamasama mendirikan suatu badan (perhimpunan) dan kumpulan harta kekayaan yang berdiri secara sendiri untuk tujuan tertentu . Hubungan antara unsur-unsur perseroan, mulai RUPS, direksi, dan komisaris dengan calon investor, kreditur, dan kreditur perusahaan.

Kamboja merupakan negara dengan sistem civil law dan statutory law system artinya walaupun kamboja memiliki sistem yang sama dengan Indonesia tapi aturan yang mengatur mengenai Perusahaan Perseroan nya berbeda. Aturan mengenai perusahaan di Kamboja diatur dalam The Council for the Development of Cambodia yang selanjutnya akan disebut sebagai CDC. CDC merupakan aturan tertinggi yang ada di Kamboja utuk saat ini, pembentukan CDC ini awalnya merupakan kerjasama antara The Cambodian Investment Board (CIB) dan The Cambodian Special Economic Zone Board yang bertujuan sebagai regulasi untuk melindungi kegiatan Investasi yang terjadi di Kamboja. Pembentukan CDC memiliki tujuan tertentu yaitu;

We value a strong client focus; cooperation within CDC and with other agencies; integrity and honesty; openness to new ideas; team work and communication

Our vision is to be the Government Investment Promotion Agency with efficient and effective work and outputs, delivering benefits to the people of Cambodia through increased investment.

Our Purpose is to manage the Cambodian Government's private sector investment policy and help attract and retain productive private sector investment.

Kamboja membagi macam-macam bentuk dari Perusahaan Perseroan kedalam 2 bentuk yaitu berdasarkan chapter 3-Limited Company and Public Limited Company bahwa kamboja menenal istilah Private Limited Company dalam article 86 Private Limited Company is a form of a limited company that meets the following requirments. Suatu perusahaan dapat dikatakan sebagai Private limited Company apabila telah memenuhu persyaratan sebagai berikut:

a) The company may have 2 to 300 shareholders. However, one person may form a company called single member private limited company. The requirements of a single member private limited company are the same manner as aprivae limited company exceper the relationship of shareholder to one another.

b) The company may not offer its shares or other securities to the public generally but may offer them to sharesholder, family members and managers

c) The company may have one or more restriction on the transfer of each class of it shares.

d) A company treated as a private limited company from the date of registration with the Commercial Register pursuant to the prescribed form provided by the Ministry of Commerce.

Article 87 Public Limited Company is a form of limited company that is authorized by this Law to issue securities to the public. Artinya perusahaan yang tergolong Public Limited Company adalah perusahaan yang menerbitkan sekuritas kepada publik atas otoritas dari Undang-Undang. Sebelum perusahaan yang dimaksud dapat dipertimbangkan untuk naik di bursa saham, Perusahaan tersebut harus menunjukkannya mengikuti berbagai standar keuangan dan akuntansi, dan menunjukkan bahwa ia telah menetapkan struktur perusahaan dalam sebuah memorandum dan anggaran dasar. Dalam aturan Law on Commercial Enterprises sama halnya dengan hukum Perusahaan Perseroan di Indonesia bahwa pada article 91 Part 2 tentang Formation of a Limited Company bahwa yang dapat mendirikan suatu Limited Company adalah One or more competent natural persons or legal persons may create a limited company by filing articles of incorporation with the Director of Companies. Sedangkan mengenai penamaan atau suatu perseroan kamboja mengklasifikasikan nama perseroan yang akan didirikan berdasarkan bentuk perseroan sebagaimana diatur dalam 
chapter 3 article 87. Penamaan tersebut diatur dalam article 92 part 2 yaitu:

The name of Private Limited Company shall include, at the end, the word, "Private Limited Company”, or an appropriate abbreviation.

The name of a Public Limited Company shall include, at its end, the words "Public Limited Compay" or an appropriate abbreviaton.

The Director of Companies shall examine the name proposed by the company and may reject any name that is confusingly similar to another previously registered name or contrary to public order, vulgar, scanlaous or otherwise inappropriate, A decision of the Director of Companies concerning the company's name is the binding and final decision.

Perusahaan perseroan terbatas (LLC) kamboja dikelola oleh pejabat dan direktur dan didanai oleh modal yang disediakan oleh pemegang saham. Itu bisa sekecil satu orang bisnis atau sebesar bisnis dengan banyak pemegang saham. Perusahaan menyediakan kerangka kerja bagi bisnis untuk memiliki properti, menandatangani kontrak, dan terlibat dalam tindakan hukum tanpa menempatkan aset para pemegang sahamnya di risiko. Perusahaan tunduk pada properti, pendapatan, penjualan, dan lainnya yang berlaku pajak. Karena perusahaan itu sendiri adalah badan hukum artifisial, ia bertanggung jawab untuk hutang perusahaan. Kecuali dalam kasus penipuan atau kelalaian, pemegang saham, direktur dan pejabat tidak dapat dianggap bertanggung jawab secara pribadi atas hutang ini. Perusahaan dibentuk melalui proses yang mengarah pada penyelesaian Anggaran Dasar kepada Kementerian terkait. Pemegang saham menikmati tanggung jawab terbatas pada jumlah nilai per saham yang belum dibayar yang tersisa. Perusahaan terbatas adalah bentuk bisnis hukum yang paling umum. Ketika LLC dibuat (disebut "penggabungan") ia memiliki identitas hukum yang berbeda dan ada secara independen dari pemilik pemegang saham dan dapat masuk kontrak, dan menuntut dan digugat atas namanya sendiri. LLC juga memiliki keabadian suksesi, yang berarti bahwa itu terus ada terlepas dari kematian, penarikan atau pensiun dari pemegang saham, sampai berakhir sesuai dengan UU tentang Usaha Komersial (LoCE) kamboja.

LLC kamboja juga telah mengatur tentang nama perseroan, modal saham, pemegang saham, pendaftaran perusahaan, direktur perushaan, pendaftaran kantor, pajak yang dapat digambarkan sebagai berikut:

\begin{tabular}{|c|c|}
\hline $\begin{array}{l}\text { Company } \\
\text { Name }\end{array}$ & $\begin{array}{l}\text { Must be unique and must } \\
\text { not include certain } \\
\text { restricted words. It may be } \\
\text { in Khmer or Latin alphabet } \\
\text { with the Latin name below } \\
\text { the Khmer name and in } \\
\text { smaller font. Limited } \\
\text { liability companies } \\
\text { registered in the Kingdom } \\
\text { of Cambodia carry the suffi } \\
\text { x ("private limited } \\
\text { company or single member } \\
\text { private limited company, } \\
\text { almost invariably } \\
\text { abbreviated to Ltd") or } \\
\text { (public limited company, } \\
\text { abbreviated to plc). }\end{array}$ \\
\hline Share Capital & $\begin{array}{l}\text { The company shall issue a } \\
\text { minimum of one thousand } \\
\text { shareswith a par value of } \\
\text { not less than KHR } 4,000 \\
\text { per share. That is, the } \\
\text { minimum share capital for } \\
\text { setting up is KHR } \\
4,000,000(\text { approximately } \\
\text { US } \$ 1,000) \text {. }\end{array}$ \\
\hline Shareholders & $\begin{array}{l}\text { The liability of each } \\
\text { shareholder is limited to the } \\
\text { share capital they have } \\
\text { invested. }\end{array}$ \\
\hline $\begin{array}{l}\text { Registered } \\
\text { Office }\end{array}$ & $\begin{array}{l}\text { A company must have a } \\
\text { registered offi ce address in } \\
\text { Kingdomof Cambodia. }\end{array}$ \\
\hline $\begin{array}{l}\text { Company } \\
\text { Directors }\end{array}$ & $\begin{array}{l}\text { There may be one or more } \\
\text { directors. Directors must be } \\
\text { a natural person, but may be } \\
\text { of any nationality, domicile } \\
\text { and residence. }\end{array}$ \\
\hline
\end{tabular}




\begin{tabular}{|c|l|}
\hline $\begin{array}{c}\text { Company } \\
\text { Registration }\end{array}$ & $\begin{array}{l}\text { A company is incorporated } \\
\text { by submitting the necessary } \\
\text { paperwork and fee to the } \\
\text { Registrar of Companies and } \\
\text { businesses at the } \\
\text { Commercial Registration } \\
\text { Department. }\end{array}$ \\
\hline Tax & $\begin{array}{l}\text { Profit tax is payable on } \\
\text { profi ts generated in } \\
\text { Cambodia. }\end{array}$ \\
\hline
\end{tabular}

Sumber : Handbook Commercial Registration, Minister of Commerce, Cambodia

Selain mengatur secara administratif perseroan kamboja juga mengatur mengenai kewenangan direktur sebagaimana dalam article 119 tentang Powers of Directors part 2 Formation of a Limited Company bahwa :

The directors shall manage the business and affairs of a company. The article of incorporation shall provide for the rights of the directors namely:

1) Propose to the shareholders an agreement of merger or consolidation between the company and any other person;

2) Appoint and remove all officers and determine the specific right for such officers: Set the salaries and other compensation of such officers;

3) Fix the salary or other compensation for directors and submit them to shareholders for approval;

4) Issue notes, bonds, debentures and other evidences of debt of the company and fix their absolute, relative and contingent characteristic;

5) Propose to shareholders the amendments or annulments to the article of incorporation;

6) Propose to the shareholders an agreement of merger or consolidation between the company and any other person;

7) Propose to the shareholders the sale of all or major part of the company's asset;

8) Propose to the shareholders a dissolution or liquidation of the company;

9) Declare dividends in accordance with accounting principles and the term of payment of each class of shares entitled to receive dividends;
10) Issue shares the company to the extent authorized in the article of incorporation and bylaws;

11) Borrow money;

12) Issue, reissue or sell security of the company;

13) Give a guarantee on behalf of the company;

14)Mortgage, hypothecate, pledge or otherwise create a security interest in all or any property of the company to secure an obligation of the compny;

15) Close account books of each financial year and propose the annual profits for submission to the shareholders and shareholders general meeting.

Penjelasan diatas menunjukan bahwa Indonesia dan Kamboja memiliki perbedaan tentang pengaturan perusahaan perseroannya masing-masing. Uraian diatas menunjukan bahwa dalam beberapa hal Indonesia dan Kamboja memiliki persamaan, hal tersebut dapat dilihat bahwa dalam keduanya samasama mengatur bahwa suatu perusahaan perseroan harus menjelaskan identitas nya sebagai status badan hukum. Indonesia mengharuskan pencantuman jenis perseroan apakah Perseroan Terbatas (PT), Perseroan Publik, dan Perseroan terbuka, sedangkan Kamboja mengatur mengenai identitas tersebut pada saat pendaftaran suatu perseroan yang menjelaskan apakah perusahaan tersebut Private Limited Company atau Public Limited Company.

\section{KESIMPULAN}

Dalam pengaturan perusahaan perseroan, Indonesia dan Kamboja memiliki beberapa perbedaan diantaranya;

1. Berdasarkan Hukum Indonesia, kata "Perseroan" berasal dari beberapa UndangUndang yang berlaku, salah satunya berdasarkan Pasal 1 ayat 1 Undang Nomo 40 Tahun 2007 Tentang Perseroan Terbatas: Perseroan terbatas, yang selanjutnya disebut Perseroan, adalah badan hukum yang merupakan persekutuan modal, didirikan berdasarkan perjanjian, melakukan kegiatan usaha dengan modal, didirikan berdasarkan 
Terakreditasi Peringkat 5 (No. SK: 85/M/KPT/2020)

perjanjian, melakukan kegiatan usaha dengan modal dasar yang seluruhnya terbagi dalam saham dan memnuhi persyaratan yang ditetapkan dalam Undang-Undang ini serta peraturan pelaksanaanya.Sedangkan Kamboja mendefinisikan suatu Perusahaan Perseroan berdasarkan jenis perseroan itu sendiri yaitu :

- Article 86 Private Limited Company is a form of a limited company that meets the following requirments.

- Article 87 Public Limited Company is a form of limited company that is authorized by this Law to issue securities to the public;

2. Indonesia membagi perusahaan perseroan menjadi 3 jenis yaitu; perseroan terbatas, perseroan terbuka, dan perseroan publik. Sedangkan Kamboja membagi perusahaan perseroan menjadi dua yaitu Private Limited Company dan Public Limited Company;

3. Pengaturan mengenai Perusahaan Perseroan di Indonesia diaitur dalam Kitab Undang-Undang Hukum Dagang Bab Ketiga Bagian Kesatu Pasal 15, Bagian Ketiga Tentang Perseroan Terbatas, Undang-Undang Nomor 19 Tahun 2003 Tentang Badan Usaha Milik Negara, Undang-Undag Nomor 40 Tahun 2007 Tentang Perseroan Terbatas. Kamboja mengatur mengenai Perusahaan Perseroan dalam Law on Commercial Enterprise, CDC pada tahun 2005.

4. Indonesia tidak membagi suatu Perusahaan Perseroan berdasrkan kewenangan kegiatan usaha yang akan dilakukan, namun Kamboja mengaur registrasi suatu Perusahaan Perseroan berdasarkan kegiatan usahanya baik dalam hal export dan import, pembagian tersebut dapat diuraikan sebagai berikut:

\begin{tabular}{|c|c|c|c|}
\hline $\begin{array}{c}\text { Business } \\
\text { Area }\end{array}$ & $\begin{array}{c}\text { Business } \\
\text { Service }\end{array}$ & Fee & $\begin{array}{c}\text { Appro } \\
\text { val }\end{array}$ \\
& & & \\
\hline
\end{tabular}

\begin{tabular}{|c|c|c|c|}
\hline $\begin{array}{l}\text { 1. Public } \\
\text { Work } \\
\text { and } \\
\text { Transpo } \\
\text { rt }\end{array}$ & $\begin{array}{l}\text { Motorbike } \\
\text { registration } \\
\text { Transport } \\
\text { business } \\
\text { permits, etc }\end{array}$ & US\$14 & $\begin{array}{l}\text { Less } \\
\text { than } 1 \\
\text { month }\end{array}$ \\
\hline 2. Tourism & $\begin{array}{l}\text { Guesthouses (no } \\
\text { more than } 5 \\
\text { rooms) } \\
\text { Food } \\
\text { stores/restaurant } \\
\text { s (no } \\
\text { more than } 50 \\
\text { chairs) } \\
\text { Tourist } \\
\text { transporting } \\
\text { means } \\
\text { (motorbike and } \\
\text { cars with no } \\
\text { more than } 5 \\
\text { seats) }\end{array}$ & $\begin{array}{l}\text { KHR 42,000 } \\
\text { KHR } 12,000- \\
52,000 \\
\text { KHR } 12,000- \\
82,000\end{array}$ & 3 days \\
\hline $\begin{array}{l}\text { 3. Industry } \\
\text {, Energy } \\
\text { and } \\
\text { Mines }\end{array}$ & $\begin{array}{l}\begin{array}{l}\text { Manufacturing } \\
\text { (garment, }\end{array} \\
\text { leather, candle, } \\
\text { etc) with } \\
\text { investment } \\
\text { capital of no } \\
\text { more } \\
\text { than KHR } 10 \\
\text { million or use of } \\
\text { machinery } \\
\text { capacity of } 12 \\
\text { cc } \\
\text { Services } \\
\text { (machinery } \\
\text { repair, } \\
\text { barber shops, } \\
\text { etc) } \\
\text { Electricity } \\
\text { production (not } \\
\text { more than } \\
\text { 75KVA) }\end{array}$ & $\begin{array}{l}\text { KHR 30,000- } \\
50,000 \\
\text { KHR 20,000- } \\
60,000 \\
\text { KHR 30,000 - } \\
70,000\end{array}$ & $\begin{array}{l}3 \text { days } \\
-\quad 2 \\
\text { weeks }\end{array}$ \\
\hline $\begin{array}{l}\text { 4. Culture } \\
\text { and Fine } \\
\text { Art }\end{array}$ & $\begin{array}{l}\text { Art } \\
\text { performance, } \\
\text { video } \\
\text { products, } \\
\text { making and } \\
\text { selling } \\
\text { sculptures, } \\
\text { advertising } \\
\text { banners } \\
\text { or posters, etc }\end{array}$ & $\begin{array}{l}\text { KHR } 7,000 \quad- \\
50,000\end{array}$ & 3 days \\
\hline $\begin{array}{l}\text { 5. Commer } \\
\text { ce }\end{array}$ & $\begin{array}{l}\text { Businesses not } \\
\text { required to pay } \\
\text { Real Regime } \\
\text { profit tax and } \\
\text { revenues of less } \\
\text { than KHR } \\
6,000,000 \text { per } \\
\text { year }\end{array}$ & KHR 5,000 & 3 days \\
\hline
\end{tabular}


Terakreditasi Peringkat 5 (No. SK: 85/M/KPT/2020)

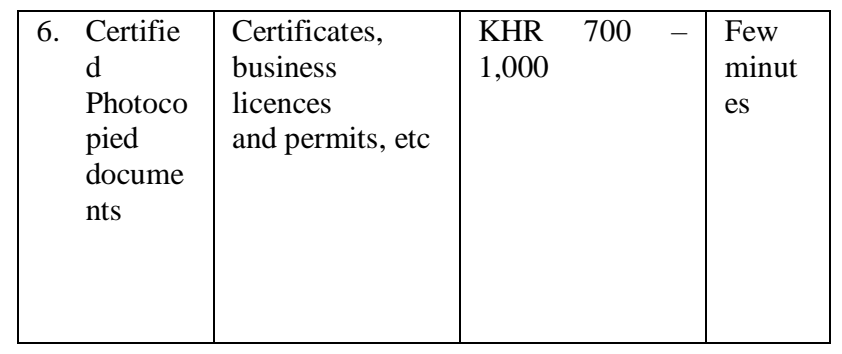

Sumber : Handbook Commercial Registration, Minister of Commerce, Cambodia

\section{DAFTAR PUSTAKA PERATURAN} UNDANGAN

\section{PERUNDANG-}

Undang-Undang No. 40 Tahun 2007 Tentang Perseroan Terbatas

Law on Commercial Enterprises, Cambodia, 2005

Handbook Commercial Registration, Minister of Commerce, Cambodia, 2007

\section{BUKU}

Abdurrahman, Muslan. Sosiologi dan Metode Penelitian Hukum, Malang : UMM Press, 2009

Chaidir, Ali. Badan Hukum. Bandung : Alumni,1991

Danang Wahyu Muhammad,dkk, Hukum Bisnis, Yogyakarta : Pustaka pelajar, 2018

Harahap, M. Yahya. Hukum Perseroan Terbatas, Jakarta: Sinar Grafika, 2011

Nadapdap, Binoto. Hukum Perseroan Terbatas, Jakarta: Jala Permata Aksara, 2009

Qamar, Nurul. Perbandingan Sistem Hukum dan Peradilan Civil Law System dan Common Law System, Makassar: Pustaka Refleksi 2010

Sigit Sapto Nugroho, dkk. Hukum Perseroan Terbatas (Prinsip Good Corporate Governance dan Doktrin Piercing The Corporate Veil), Solo : Pustaka Iltizam, 2017

Soemitro, Rahmad. Penuntun Perseroan Terbatas dengan Undang-Undang Pajak Perseroan, Bandung : Eresco, 1979

Widjaya, I.G. Ray. Hukum Perusahaan Perseroan Terbatas. Jakarta: Megapoin Kesaint Blanc, 2002

\section{JURNAL}

Andrew D. E. Lewis, Albert Roland Kiralfy, dkk, Common Law, https://www.britannica.com /topic/common-law

The University of Melbourne, "Southeast Asian Legal Research Guide: Introduction to Cambodia \& its Legal System",

http://unimelb.libguides.com/c.php?g $=402982 \& \mathrm{p}=4785153 \# \mathrm{~s}-1 \mathrm{~g}-\mathrm{box}-$ wrapper-17721308

\section{INTERNET}

http://www.cambodiainvestment.gov.kh/abou t-us/who-we-are.html

https://www.b2b-cambodia.com/industryoverviews/businessstartup/\#1464418768534-4b839fb749aa

https://www.oecd.org/daf/ca/CorporateGovernance-Frameworks-CambodiaLao-PDR-Myanmar-Viet-Nam.pdf

Kedutaan Besar Republik Indonesia di Phnom Penh, Kerajaan Kamboja, "Pavilion Indonesia dapat Penghargaan pada Cambodia Travel Mart 2019”, https://kemlu.go.id/phnompenh/id/ne ws/2542/pavilion-indonesia-dapatpenghargaan-pada-cambodia-travel$\underline{\text { mart-2019 }}$ 